\title{
Customized Employment: A Systematic Approach To Community Integration And Strategies To Obtain Competitive Employment
}

\author{
Nanette Edeiken-Cooperman \\ Saint Joseph's University \\ Department of Special Education \\ 5600 City Avenue, Merion Hall 216, Philadelphia, PA 19131
}

\begin{abstract}
The purpose of this qualitative, multimethod study was to investigate the role of an agency that implements a systematic planning approach to assisting individuals with disabilities to integrate into the community and to obtain competitive or customized employment. The agency that was part of this study has implemented the philosophy of Employment First and has found that the experience of customized employment maximizes the independence and self-determination of the individual while at the same time promoting a positive self image. Data was collected using semi-structured interviews and direct non-participant and participant observations with the intent to exemplify that customized employment is a successful, alternate strategy for job seekers with significant disabilities when the demands of integrated employment become a barrier. The results revealed that a national initiative related to Employment First is a necessity in order to promote the successful employment of all individuals with disabilities earning minimum wage or higher.
\end{abstract}

Keywords: Customized employment, Employment First, intellectual disabilities, transition

\section{INTRODUCTION}

Employment for most of the general population is a road that leads to a successful and prosperous life. It is an avenue to receive income that assists in providing opportunities to have social engagement and a positive quality of life as a contributing member of our society as well as funding independent housing. Despite these essentials and realities, the rate of unemployment for individuals with disabilities continues to be the highest of any minority group in the United States (Niemiec, Lavin, \& Owens, 2009). According to a recent survey completed by the Kessler Foundation and the National Organization on Disability, there is a $30 \%$ gap in employment rates between individuals with disabilities and those without disabilities who are of working age (Kessler Foundation/National Organization on Disability, 2010a). Transition practices from school to post-school life have generally not been effective in assisting this population to procure jobs that are at or above minimum wage and that are community based and integrated within the general working population.

In recent years there have been developments that support the shift from facility-based employment to community-based employment. The outcome of these developments has contributed to increased expectations for individuals with disabilities and their capacity to locate competitive employment (Lueking, 2011). This situation has driven many states to adopt policies that are focused on Employment First. This movement is based on the presumption that individuals with disabilities should have the opportunity to participate in competitive, integrated employment with the goal being equality in the labor force and a maximum level of independence. Of the 21 states that adopted Employment First policies in 2011, the average percentage of individuals with disabilities who were employed in an 
integrated employment environment was $32 \%$, as compared to $20 \%$ within the states that had not adopted this initiative (Callahan, Griffin, \& Hammis, 2011). Strategies consisted of guiding principles, policies, and practices and as a priority for state funding this information was distributed through state statue, regulations, or operational procedures (Niemiec et al., 2009).

According to a memorandum written by Romano (2009), the past Assistant Secretary for the Department of Labor's Office on Disability Employment Policy (ODEP), "sheltered employment with sub-minimum wages and non-work 'day activities' are not longer acceptable employment outcomes" (as cited in Niemiec et al., 2009, p. 139). Although funding is necessary to accomplish evidence-based education and positive outcomes for individuals with disabilities, it is also essential to have higher expectations and a positive outlook in order to empower these individuals and working-age adults to lead prosperous lives.

One strategy that is currently being implemented in order to accomplish a successful transition from school to competitive, integrated employment is Customized Employment (CE). Customized Employment is the process of determining the strengths and interests of an individual with a significant disability and then carving out a job that meets the needs of that individual as well as the employer. This requires a balance between both the choice and interests of the individual and the labor needs of the employer (Elinson, Frey, Li, Palan, \& Horne, 2008). The Office of Disability Employment Policy, a division of the U.S. Department of Labor, first defined CE as an initiative in the Federal Register (2002) that read as follows:

Customized employment means individualizing the employment relationship between employees and employers in ways that meet the needs of both. It is based on an individualized determination of the strengths, needs, and interests of the person with a disability, and is also designed to meet the specific needs of the employer. It may include employment developed through job carving, self-employment, or entrepreneurial initiatives, or other job development or restructuring strategies that result in job responsibilities being customized and individually negotiated to fit the needs of individuals with a disability. Customized employment assumes the provision of reasonable accommodations and supports necessary for the individual to perform the functions of a job that is individually negotiated and developed. (Federal Register, 2002)

The traditional labor market approach to competitive employment typically has not been very successful for individuals with disabilities. This can be attributed to the lack of individualization used to focus on the contributions, skills, and personal characteristics of the individual (Condon \& Callahan, 2008). Therefore, a benefit of CE is that the process begins with an inventory of the strengths and interests of the individual with a disability. A critical component of $\mathrm{CE}$ is that an individual with a disability will be gainfully employed in a job that has been personalized based on the needs of that individual as determined by this inventory or vocational profile and that their pay will be at least minimum wage. The employer will benefit from having a qualified employee who will perform job responsibilities that are required at that specific location.

Customized Employment implies flexibility on the part of the employer as well as a responsibility for the job coach to modify the parameters and desired outcomes of a job based upon the evolving skills and interests of the individual as he or she gains work experience. According to Harvey, Szoc, Dela Rosa, Pohl, and Jenkins (2013), CE involves four major components: discovery, job search planning, job development and negotiation, and post- 
employment support (Fig. 1). This approach allows for the individual in consultation with an employment specialist to discuss job responsibilities that match the individual's skills (Inge, 2007). In order for applicants with disabilities to achieve successful outcomes, it is essential that employers believe that an individual with a disability can make valuable contributions to our society and specifically to competitive employment. In addition, the positive effects of CE require that the individuals be treated with dignity and respect (Harvey et al., 2013).

The aim of this qualitative study was to examine whether CE is a successful, alternate strategy for job seekers with significant disabilities when the demands of integrated employment become a barrier.

\section{METHOD}

This study involved qualitative multi-method inquiry through the use of case study analysis to gain insight into the agency being studied as well as other methods of data collection. The systematic planning process this agency was studied in reference to several individuals who were receiving services from this agency. The services provided include support to individuals with intellectual, developmental, and other disabilities and assist in the process of community engagement and vocational training with the goal of obtaining integrated competitive employment. In order to protect the privacy of the individuals and the agency, the agency will be referred to as Agency, and the names of the participants have been changed. Purposive sampling was implemented to choose individuals, situations, and events as a means of developing an understanding of the processes being implemented by the Agency.

Data was collected using semi-structured interviews, direct non-participant observation, and participant observation. Both types of observation were used dependent on the situation. According to Krathwohl (2009), acting as a participant "reduces the obtrusiveness" yet nonparticipant observation "provides the researcher with the freedom to concentrate entirely on observation and on the significance of what is occurring" (pp. 262-263). There were situations when actively participating included the researcher as a member of the group in order to avoid the behavior of the participants changing because they were aware that they were being observed. The participants appeared to be comfortable with the inclusion of the researcher into the group when we were in the community, which enhanced the conversations and provided valuable information in reference to their experiences and preferences related to integrated competitive employment. In contrast, there were other times that direct observation as a nonparticipant was more appropriate. An example was when one of the individuals was actively participating in a job when that individual was being paid as an employee. Active participation would have been inappropriate and would have compromised the independence of the individual when completing their job responsibilities.

\section{PARTICIPANTS}

The individuals who participated in this qualitative study were receiving support from an agency that is waiver approved in Philadelphia, PA. All individuals were a minimum of 18 years of age and had been referred to the Agency from either the Intellectual Disability Services of Philadelphia or the Office of Vocational Rehabilitation. Once this referral process was complete, participants completed an interest inventory or the alternative was that a vocational interest profile was developed through an interview with the individual in order to determine their interests and strengths. 
This particular Agency placed each individual into one of three stages in the community dependent on his or her intellectual functioning levels and experience, as well as his or her capacities and availability of jobs related to his or her interest. The three designated levels were community engagement, volunteer jobs, and competitive employment. The development of these stages followed a systematic approach to introducing the individual to the requirements of competitive employment as well as independent travel training.

\section{DATA ANALYSIS}

Participants read and signed a consent form that was approved by the researcher's University Institutional Review Board (IRB) that explained that anonymity and confidentiality would be maintained. The script that was read to each individual was also approved by the University IRB and explained the purpose of the study and how the results would be documented and published (Appendix). In addition, each individual was given the option of stopping the interview and observation at any time during the process should they feel uncomfortable or no longer wish to participate.

All interviews were completed face-to-face using a semi-structured interview protocol after observations had been completed (Appendix). According to Corbin and Strauss (2015), it is essential to combine observations with interviews in order to confirm interpretations of witnessed actions or interactions. The process involved for data analysis included (a) reviewing data by reading and re-reading responses and observations, (b) analyzing and categorizing the data by identifying common and unique themes or patterns, and (c) interpreting the data for major findings.

\section{RESULTS}

A significant amount of time was spent as an active participant observer with the individuals who were involved in community engagement. There were four participants, two females and two males and the ages ranged from 22 years to 68 years old. It was evident through interview and conversation that all of the stakeholders were interested in obtaining a job and interacting with the general population. Three of the participants were living in a supervised arrangement with one was living at home with his parents. The individual who was observed in a CE placement was 45 years old, travel trained, and also living in a supervised placement.

Data were reviewed by reading and re-reading responses and observations and analyzed and categorized by identifying common and unique themes or patterns, and interpreting the data for major findings. The following themes were determined through this process: independence, jobs, wages, socialization, and self-determination. The themes appeared to be interconnected in that the eventual obtainment of a job would provide opportunity for competitive wages which would in turn lead to independence and additional opportunity for socialization. Self-determination was most often discussed in reference to choice or decisionmaking about the type of job that was preferred. These themes will be discussed in the participant profiles.

\section{PROFILES}

In the following profiles the findings are discussed in reference to themes and observations. Profiles for each of the individuals were developed by the Agency and included the individuals' interests, the supports that were necessary in the work environment, and the jobs that would provide successful outcomes. The next step was that goals were developed with the individual in order to establish an individualized process to obtaining employment. These varied 
dependent on the individual skill levels and experience of the individual and included such goals as increasing skills related to money, independent travel, and time management. Goals were treated as an active process and reviewed regularly with the individuals in order to adapt to changing skill levels as well as changes to the individuals' environment and personal issues. The final step was to determine in what level or stage of community integration each individual should be placed; community engagement, volunteer job, or competitive employment.

\section{Cindy}

This individual was a 43-year-old female who lived in a supervised living placement at the time of this study. The environment was an apartment with three other females who all functioned on the moderate to severe intellectual functioning level. Her goals consisted of appropriate conversation and socialization skills, independent travel training, and finding a job. At the time of the interview Cindy was volunteering at a pet store which was her choice of job. She enjoyed feeding the animals, cleaning their cages, and holding them to give them affection. The case worker believed that Cindy was ready to work in a competitive employment position but they were having difficulty finding a job that paid at or above minimum wage. Cindy expressed in the interview that she loved animals and that her other favorite environment was church. She enjoyed going to church for mass or for any of the activities that they sponsored, e.g., concerts. Cindy has some family in the geographical area where she lives, and will often visit them. These visits had a positive effect on Cindy and she looked forward to them. She stated that she wanted to increase the number of visits if possible so that she could have time with her nephew.

Cindy clearly possessed most of the skills required for CE and spoke openly about the need for a job. She enjoyed buying things for herself and her family and wages would assist with her buying power. She was hoping that her volunteer job would eventual become a paid position.

\section{Andy}

This individual was 22-years-old at the time of the interview and observation was living at home with his parents and family. His goals included increasing his community involvement and exposure, increasing his knowledge of money skills in order to make purchases independently, and to begin discussion concerning where he would like to work or volunteer.

The day of the interview and observations, Andy was quite upset concerning a conversation with his mother and how he believed he as being treated. He wanted to stay in the current community engagement program but his mother disagreed with this decision. It was in his opinion that he should have input into where he receives services and what type of job would be appropriate for him. The Community Participation Team Leader had an appropriate conversation with this individual and attempted to give him the language to speak to his parents about including him in the decision making process in reference to his future and his experiences. It was clear that this individual was attempting to be self-determined and that he needed additional experience in community engagement prior to gaining competitive employment. Independence was a priority for him, but his family had made the decision to have him live in their home or the home of a family member for the immediate future. Andy was quite agitated because of the lack of respect his mother had for him in reference to knowing what he wants in the future and how he was choosing to lead his life. It was apparent that this situation was not new, but was one that the Agency and the individual were coping with and having limited success or change. 
Andy exemplified an individual who possessed self-determination and motivation, yet was being held back by his family and lack of exposure to the acceptance of responsibility and independence. The employees of the Agency appeared to be working through the issues with Andy and providing him with suggestions for strategies.

\section{Liam}

Liam was a 68-year-old male who was living with his wife in a supervised living arrangement at the time of this study. Both he and his wife were life-time residents of an institution prior to its closing, and functioned on the moderate intellectual level. He spoke openly concerning his life with his wife and their interests in cooking and watching specific shows on television. He was observed with his wife and it is clear that they have a loving and caring relationship with each other. Liam travels independently and had a goal of increasing his knowledge of time to improve these skills. The Agency was in the process of exploring employment options with Liam through the use of a picture journal. In addition, he was encouraged to have appropriate conversation with his peers and others about things that were meaningful and important in his life.

The time spent with Liam was enjoyable and it was clear that he could converse appropriately in reference to his wants and needs for the future and for the needs of his wife and partner. He desperately wanted a job and to make money so that he could buy things on his own both for himself and his wife. The environments that he seemed to enjoy included church and the library. He also expressed a desire to work in a restaurant setting cleaning tables, as well as serving others. Liam had a pleasant personality and enjoyed singing holiday songs that were appropriate for that time of year.

This individual has the desire and motivation to work, yet seemed to be a victim of his circumstance of being a resident in an institution and receiving limited education and training. His transition to the community living arrangement was accomplished with close supervision. Both he and his partner had significant health issues, but again they were being treated with assistance from the supervising agency.

\section{Robert}

This individual was a 45-year-old male who functioned on a moderate intellectual level. He was currently employed at a major hotel chain and was being paid above minimum wage for work that included maintenance and cleaning, primarily in the employee cafeteria and lounge. Robert independently traveled to work and clocked-in using a time card. During all observations Robert completed his tasks appropriately and successfully, although he did occasionally break to have conversations with the researcher as well as employees of the hotel who were familiar to him. It was indicated in his profile that he needs to improve his appropriate social skills with women and that there had been some issues in the past with an obsession with feet.

Robert does not have any family in the area and lived independently in a supervised placement. It was evident through both interview and observation that Robert has been given options and choices and enjoys the independence of earning wages and the ability to spend those wages on his wants and needs. 


\section{DISCUSSION}

In order to accomplish a shift from sheltered to community-based, integrated employment it is essential to align policies, funding, and practices within federal and state agencies. According to Rogan and Rinne (2011), "Evaluation and funding should be tied to desired outcomes, and annual targets should be set to track increases in integrated employment and concurrent decreases in facility-based and nonwork services" (p. 257). This would require a national comprehensive shift in practices and thinking as well as a total organizational change for service providers. It was reported by Callahan, Griffin and Hammis (2011), that although the number of individuals with significant disabilities has remained consistent over the past several years, the percentage of individuals being placed in integrated employment has decreased. The Employment First initiative should serve as evidence that individuals with disabilities have the ability to participate in integrated, community based employment and to be contributors to our democratic society.

The agency that was part of this study has implemented the philosophy of Employment First and has found that the experience of customized employment maximizes the independence and self-determination of the individual while at the same time promoting a positive self image. This process involves, as stated by Condon and Callahan (2008), assuming that individuals with disabilities are ready to be employed and "all that is needed is to discover each individual's ideal conditions of employment and potential contributions" (p. 95).

It is essential for the benefit and positive outcomes of stakeholders to begin appropriate transition planning with the secondary and post-secondary institutions that emphasize the skills necessary to be gainfully employed. It was the belief of Niemiec et al. (2009) that educational curricula should be re-designed to include Employment First policies and supported with customized employment practices. This would eliminate the need for community engagement programs and provide an immediate opportunity to participate in competitive employment for all individuals with disabilities. A primary requirement would be a redesign of policies and practices that are currently implemented in secondary and postsecondary placements.

The participants in this study had an average age of over 40 and were just in the initial stages of investigating what type of employment would be appropriate. This can be attributed to their involvement in educational programs that did not appropriately plan for their transition to an integrated employment opportunity. It is essential that educational institutions effectively implement transition plans that look at the capacity of these individuals, rather than their deficits, in order to diminish the time that is misused. These participants clearly experienced underachievement related to employment because of the limited opportunities available and their limited choice related to competitive employment. The findings of Timmons, Hall, Bose, Wolfe, and Winsor (2011) revealed that "school based staff become the conduit to early employment experience" and that research has shown that "strong teacher advocacy for work experience correlates positively with successful integrated-employment outcomes for transition-age students" (p. 295).

It is essential in order to continue to improve and shape the lives and futures of those individuals with disabilities, that we engage in the process of partnerships with companies that are willing to look at the strengths of these individuals. Because of the documented difficulties with generalization of skills from one environment to another, the philosophy that facility based employment being a precursor or pre-requisite to community employment is a myth. 
Therefore, we must change our thinking in reference to a vision and mission for the future to include strategies for organizational changes that focus on integrated employment outcomes. A federal Employment First initiative would accomplish this mission and should become the first and only option for these individuals.

\section{LIMITATIONS OF THE PRESENT STUDY}

The limitation of the study was that only one agency was studied and this was not a longitudinal study. Therefore, this study cannot be generalized on a state or national level. The Employment First movement should be studied in more depth and the processes implemented by other agencies over a longer period of time would be more effective in determining outcomes.

\section{References}

Callahan, M., Griffin, C., \& Hammis, D. (2011). Twenty years of employment for persons with significant disabilities: A retrospective. Journal of Vocational Rehabilitation, 35, 163-172. doi: 10.3233/JVR-2011-0565

Condon, E., \& Callahan, M. (2008). Individualized career planning for students with significant support needs utilizing the Discovery and Vocational Profile process, cross-agency collaborative funding and Social Security Work Incentives. Journal of Vocational Rehabilitation, 28, 85-96.

Corbin, J., \& Strauss, A. (2015). Basics of qualitative research: Techniques and procedures for developing grounded theory (4th ed.). Los Angeles, CA: Sage.

Elinson, L., Frey, W. D., Li, T., Palan, M. A., \& Horne, R. L. (2008). Evaluation of customized employment in building the capacity of the workforce development system. Journal of Vocational Rehabilitation, 28, 141-158.

Federal Register, US Department of Labor, Washington, DC, 67(123)(2002), pp. 43154-43149.

Harvey, J., Szoc, R., Dela Rosa, M., Pohl, M., \& Jenkins, J. (2013). Understanding the competencies needed to customize jobs: A competency model for customized employment. Journal of Vocational Rehabilitation, 38, 77-89.

doi: $10.3233 / J V R-130622$

Inge, K. J. (2007). Demystifying customized employment for individuals with significant disabilities. Journal of Vocational Rehabilitation, 26, 63-66.

Kessler Foundation/National Organization on disability (2010a). 2010 Survey of Americans with Disabilities. New York: Harris Interactive. Retrieved from http://www.2010disabilitysurveys.org/indexold.html

Krathwohl, D. R. (2009). Methods of educational and social science research: The logic of methods ( ${ }^{\text {rd }}$ ed.). Long Grove, IL: Waveland Press, Inc.

Luecking, R. G. (2011). Connecting employers with people who have intellectual disability. Intellectual and Developmental Disabilities, 49(4), 261-273.

Niemiec, B., Lavin, D., \&, Owens, L. A. (2009). Establishing a national Employment First agenda. Journal of Vocational Rehabilitation, 31, 139-144. doi:10.3233/JVR-2009-0483

Rogan, P., \& Rinne, S. (2011). National call for organizational change from sheltered to integrated employment. Intellectual and Developmental Disabilities, 49(4), 248-260. doi: 10.1352/1934-9556-49.4.248

Timmons, J. C., Hall, A. C., Bose, J., Wolfe, A., \& Winsor, J. (2011). Choosing employment: Factors that impact employment decisions for individuals with intellectual disability. Intellectual and Developmental Disabilities, 49(4), 285-299. doi: 10.1352/1934-9556-49.4.285 


\section{Figure 1}

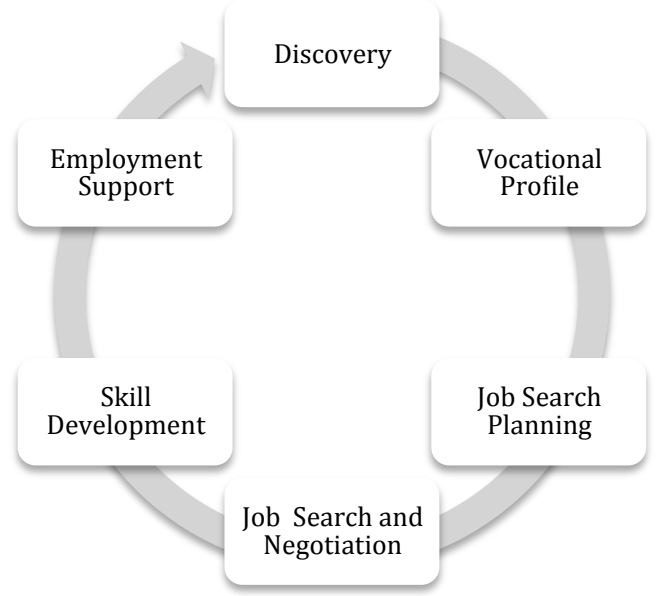

APPENDIX

\section{Script}

I am doing a research study about job training. A research study is a way to learn more about this particular topic.

If you decide that you want to be part of this study, you will be asked to allow me to watch you travel to work and watch you doing your job. I would also like to interview you to ask you questions about your job. When I ask you questions, I would like to record your answers on a small machine so that I can easily remember what you told me.

There are some things about this study you should know. There are procedures, things that may take a long time, other possible risks and discomforts, etc.

If you do not want to be in this research study, you do not have to. Just tell me that you do not want to work with me. If we begin this work together and you decide you would like to stop, just tell me and we can stop at any time.

When I am finished with this study I will write a report about what was learned for a paper that I am writing. This paper will not include your name or that you were in the study.

You do not have to be in this study if you do not want to be. If you decide to stop after you begin, that's okay too.

If you have any questions about your rights as a participant in this research you may contact the Saint Joseph's University Institutional Review Board (IRB). You can reach the Research Compliance Coordinator, Jena Fioravanti Burkett, at jfiorava@sju.edu, or by phone at (610) 660-1298.

If you decide you want to be in this study, please print and sign your name.

\section{Interview Protocol}

1) What kind of job would you like to have?

2) Did you receive training for this job when you went to school?

3) Have you received training for this job at St. John's or are they teaching you at the job site? 
4) What are your hobbies or what do you like to do when you are not working?

5) How do you get to work? Do you take public transportation? How did you learn to take public transportation?

6) What do you like best about your job?

7) Do you need assistance to complete your job responsibilities?

8) What other job would you like to explore? 